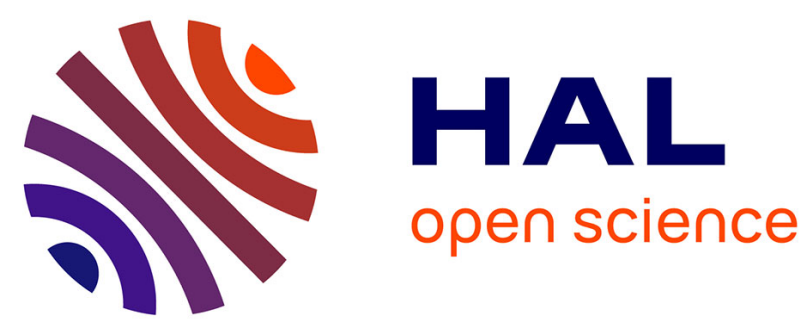

\title{
CONVOY ELECTRONS IN COINCIDENCE WITH OUTGOING PROJECTILE CHARGE STATES OF Ni $(15.6 \mathrm{MeV} / \mathrm{u})$
}

\author{
J. Kemmler, O. Heil, C. Biedermann, P. Koschar, H. Rothard, K.
}

Kroneberger, K. Groeneveld, I. Sellin

\section{To cite this version:}

J. Kemmler, O. Heil, C. Biedermann, P. Koschar, H. Rothard, et al.. CONVOY ELECTRONS IN COINCIDENCE WITH OUTGOING PROJECTILE CHARGE STATES OF Ni $(15.6 \mathrm{MeV} / \mathrm{u})$. Journal de Physique Colloques, 1987, 48 (C9), pp.C9-223-C9-226. 10.1051/jphyscol:1987935 . jpa00227353

\section{HAL Id: jpa-00227353 https://hal.science/jpa-00227353}

Submitted on 1 Jan 1987

HAL is a multi-disciplinary open access archive for the deposit and dissemination of scientific research documents, whether they are published or not. The documents may come from teaching and research institutions in France or abroad, or from public or private research centers.
L'archive ouverte pluridisciplinaire $\mathbf{H A L}$, est destinée au dépôt et à la diffusion de documents scientifiques de niveau recherche, publiés ou non, émanant des établissements d'enseignement et de recherche français ou étrangers, des laboratoires publics ou privés. 
CONVOY ELECTRONS IN COINCIDENCE WITH OUTGOING PROJECTILE CHARGE STATES OF Ni (15.6 MeV/u)

J. KEMMLER, O. HEIL, C. BIEDERMANN, P. KOSCHAR, H. ROTHARD,

K. KRONEBERGER, K.O. GROENEVELD and I.A. SELLIN ${ }^{(1)}$

Institut für Kernphysik der Joh. Wolfg. Goethe-Universität, August-Euler-Strasse 6. D-6000 Frankfurt-am-Main 90, F.R.G.

RESUME: Nous avons etudié le nombre des electrons convoyés $Y_{e}\left(q_{f}\right)$ en fonction de 1 'épaisseur $(p x)$ des cibles de carbon pour des projectiles incidents $\mathrm{Ni}_{i}{ }^{+}(15.6 \mathrm{MeV} / \mathrm{u})$ avec $\mathrm{q}_{i}=27$ et 28 en coincidence avec les projectiles emergeant de la charge $q_{f}=28$ et 27 . Simultanément nous avons mesure la distribution d'etats de charge $F\left(q_{f}, p x\right)$ en fonction de la charge incident $q_{i}$. Le domaine d'equilibre de charge est obtenu pour une epaisseur de cible plus grande que $650 \mu \mathrm{g} / \mathrm{cm}^{2}$. Dans le cadre du model des électrons convoyés la $\rho x$ dependance de $Y_{e}\left(q_{i}, q_{f}\right)$ peut etre expliquer si on tiend compte les deux processus ECC et ELC. Il faut introduire une longueur de transport $\lambda_{C}$, qui est douce fois plus grande que la longueur de la atténuation $\lambda_{e}$ des electrones libres.

ABSTRACT: We have studied the target thickness $(\rho x)$ dependence of the convoy electron yield $\mathrm{Y}_{e}\left(q_{f}\right)$ for the incident projectiles $\mathrm{Ni} q^{+}(15.6$ $\mathrm{MeV} / \mathrm{u}$ ) with $q_{i}=28$ and 27 on carbon foils in coincidence with the outgoing projectiles with charge $q_{f}=28$ and 27 . Simultaneously the charge state evolution $F\left(q_{f}, \rho x\right)$ dependent on the incident charge $q_{i}$ has been measured. For this collision system the charge state distribution saturates for target thicknesses larger than $650 \mu \mathrm{g} / \mathrm{cm}^{2}$. In the framework of the model for convoy electron production and transport the $\rho x$ dependence of the yield $Y_{e}\left(q_{i}, q_{f}\right)$ can be explained by assuming ECC and ELC processes. A transport length $\lambda_{C}$ must be introduced, which is twelf times larger than the attenuation length $\lambda_{e}$ obtained with isotachic free electrons.

In the last years great experimental evidence had been achieved that convoy electron production takes place in the bulk of the solid. Therefore the last-layer model for convoy electron production was discarded $[1]$.

If the convoy electrons are formed by the charge exchange processes of the projectile ion inside the solid the question arises how these electrons keep still correlated to the projectile ion in spite of the elastic and inelastic scattering processes inside the solid. The attenuation length for free electrons $\lambda_{e}$ extends from several $A$ for

(1) Oak Ridge National Laboratory and University of Tennessee, Oak Ridge, TE 37831. U.S.A. 
low energetic electrons to $100 \mathrm{~A}$ for electrons of $10 \mathrm{keV}$ [2]. This is in general less than the mean free path for charge exchange $\lambda_{\mathrm{cc}}$ of heavy projectile ions.

In a recent measurement of the convoy electron yield $\mathrm{Y}_{\mathrm{C}}$ for $\mathrm{Ni}^{24+}$ and $\mathrm{Ni}{ }^{26+}$ ions (Ep=15.2 $\mathrm{MeV} / \mathrm{u}$ ) on carbon and aluminum foils the glow increase of the yield $\mathrm{Y}_{\mathrm{C}}$ has been interpreted as an enhanced transport length for convoy electrons. A value for $\lambda_{c}$ was obtained which is 20 times larger than $\lambda_{e}$ for isotachic free electrons [3].

For the interpretation of this result the charge exchange processes inside the solid had not been considered. Therefore it was not clear, if the $\rho x$ dependent increase of $Y_{c}$ only describes the evolution of a charge state which produces mainly convoy electrons or is related to a real enhanced transport length.

To clear this situation we have measured the $\rho x$ dependence of the convoy electron yield $\mathrm{Y}_{\mathrm{e}}\left(\mathrm{q}_{\mathrm{f}}\right)$ for $\mathrm{Ni}^{+}{ }^{+} \quad\left(\mathrm{E}_{\mathrm{p}}=15.6 \mathrm{MeV} / \mathrm{u}\right)$ with the incident charge states $q_{i}=27$ and 28 in coincidence with projectiles of the outgoing charge state $q_{f}=27$ and 28 . Also the evolution of the charge state distribution $F\left(q_{f}\right)$ (fig. 1) was recorded. The experimental arrangement is the same than described in ref. [4].

The yield $\mathrm{Y}_{e}\left(q_{f}\right)$ has been determined by integrating the electron velocity distribution over an interval of $\pm 4 v_{B}$ centred at the peak

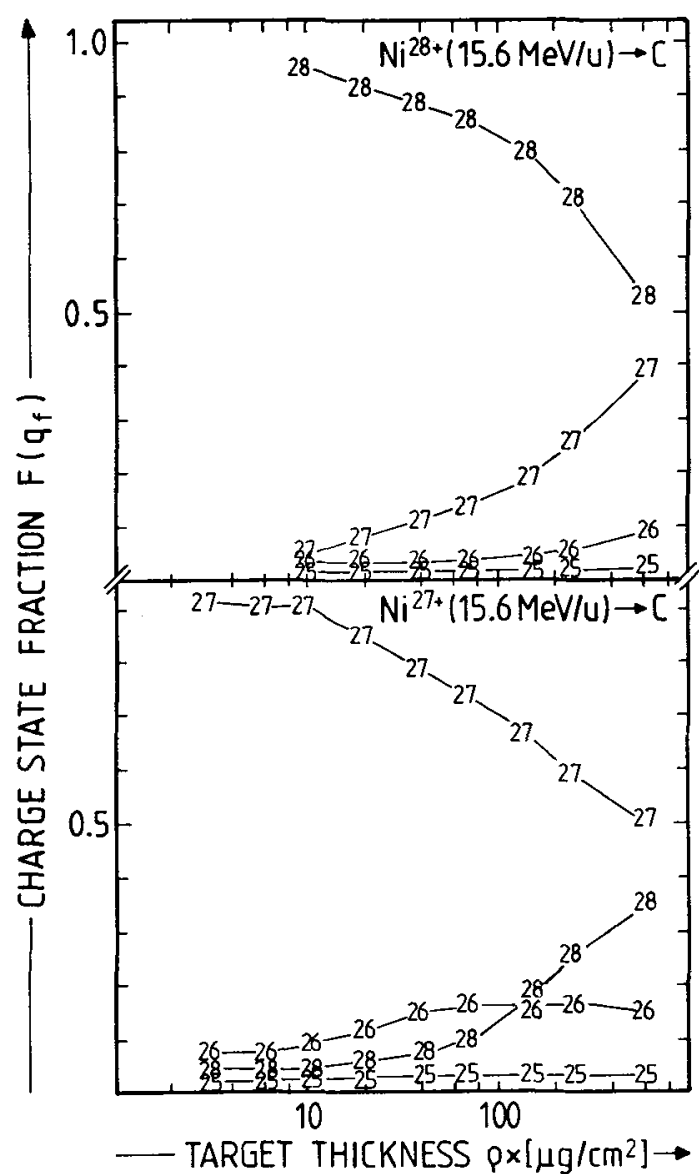

Fig. 1: Charge state distribution $\mathbf{F}\left(\mathbf{q}_{\mathbf{f}}\right)$ for the incident projectile ions $\mathrm{Ni}^{28+}$ (top) and $\mathrm{Ni}^{27+}$ (bottom) $E_{p}=15.6 \mathrm{MeV} / \mathrm{u}$ on carbon foils. The numbers denote the outgoing charge states $q_{f}$. The lines are drawn to guide the eye. 
maximum and point by point subtraction of a linear background arising from ionisation electrons. The number of convoy electrons were normalized to the total number of projectiles $N=\Sigma N\left(q_{f}\right)$ associated with all final charge states.

The evolution of the yields $\quad y_{e}\left(q_{i}=28, q_{f}=28\right)$ and $\mathrm{Y}_{\mathrm{e}}\left(\mathrm{q}_{\mathrm{i}}=27, \mathrm{q}_{\mathrm{f}}=27\right)$ (fig. 2) proceeds much faster and into a different direction than the evolution of the related charge state fractions $q_{f}=28$ and 27. In contrast the yields $\quad Y_{e}\left(q_{i}=27, q_{f}=28\right)$ and $Y_{e}\left(q_{i}=28, q_{f}=27\right)$ increase in the same way as the outgoing charge $q_{f}$.

Assuming the model of charge exchange from Allison [5] the mean free path $\lambda_{\text {cc }}$ for the loss of one electron $\left(\mathrm{Ni}^{27+} \rightarrow\right.$ $\mathrm{Ni}^{28+}$, and for the capture of one electron $\left(\mathrm{Ni}^{28+} \rightarrow \mathrm{Ni}^{27+}\right)$ was found to be nearly equal, with $\lambda_{\mathrm{cc}} \approx 650 \mu \mathrm{g} / \mathrm{cm}^{2}$. Introducing the charge exchange processes in a model for convoy electron production [4] we can determine the relative contribution of electron loss to continuum (ELC) and electron capture to continuum (ECC) and the transport length $\lambda_{C}$.

If the convoy electrons

in the case of $Y_{e}\left(q_{i}=28, q_{f}=28\right)$ and $Y_{e}\left(q_{j}=27, q_{f}=27\right)$ are produced by pure ECC and $\lambda_{C}=\lambda_{e}$, after a very rapid increase the yield $Y_{e}$ should follow the dependence of the incident charge state $q_{i}$. In the case of pure ELC the $\rho x$ dependence of the yield should follow the charge

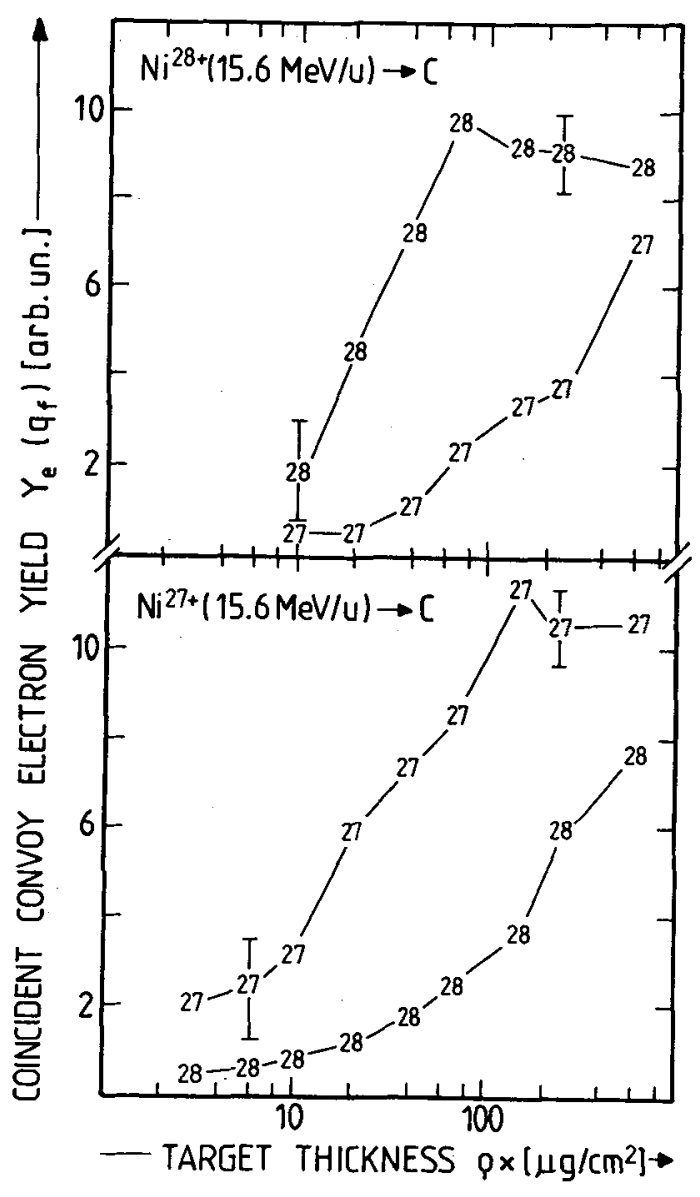

Fig. 2: Target thickness $(\rho x)$ dependence of the convoy electron yield $\mathrm{Y}_{\mathrm{e}} \mathrm{lq}_{\mathrm{f}}$ for the incident projectile ions $\mathrm{Ni}^{28+}($ top) and $\mathrm{Ni} 27+$ (bottom) $E_{p}=15.6 \mathrm{MeV} / \mathrm{u}$ in coincidence with projectiles of the outgoing charge states $q_{f}=28$ and 27 . The lines are drawn to guide the eye. 
fraction $F\left(q_{f-1}\right)$. Therefore in the scope of the used model the increase of $Y_{e}\left(q_{i}=28, q_{f}=28\right)$ cannot be explained only by assuming ELC events, because the responsible $F\left(q_{f-1}\right)$ fraction increases to slow to explain the data. If a contribution of ECC and ELC is permitted the fitting procedure leads to a portion of $50 \% \mathrm{ECC}$ and ELC. The increase of the yield point to an enhanced transport length with $\lambda_{C}=24 \pm 5$ $\mu \mathrm{g} / \mathrm{cm}^{2}$. The comparable value for isotachic free electrons is $\lambda_{\mathrm{e}} \approx 100 \mathrm{~A}$ [2]. Interpreting the increase of $Y_{e}\left(q_{i}=28, q_{f}=28\right)$ as an indication for an enhanced transport length $\lambda_{C}$ of the convoy electrons we find that

$$
\lambda_{\mathrm{cc}}>\lambda_{\mathrm{c}}>\lambda_{\mathrm{e}}
$$

These results are obtained from a simple Ansatz, which does not include any type of excitation process of the projectile electrons. But the found enhanced transport length for convoy electrons supports the concept of refocusing of electrons which accompany higly charged ions in solids [6].

Many stimulating discussions with Wolfgang Meckbach Bariloche/Argentina and Peter Sigmund odense/Danmark are gratefully acknowledged. We appreciate the support of P.Mokler and his group at GSI/Darmstadt during our experiment.

This work has been funded by the German Federal Minister for Research and Technology (BMFT) under the contract $\mathrm{nr}$. 06 OF $173 / 2 \mathrm{Ti} 476$. Support by NSE/Washington, CNEA Buenos Aires, DFG/Bonn, NATO/Brussells and GSI/Darmstadt is gratefully acknowledged.

\section{References}

$$
\begin{aligned}
& \text { M.Breinig, S.B.Elston, S.Huldt, L.Liljeby, C.R.Vane, } \\
& \text { S.D.Berry, G.A.Glass, M.Schauer, I.A.Sellin, G.D.Alton, } \\
& \text { S.Datz, R.overbury, R.Laubert, M.Suter, }
\end{aligned}
$$
Phys. Rev. Lett. $\underline{48}, 593,(1982)$

$$
\text { C.J.Powell, Scan. Electr. Microsc. IV , 1649, (1984) }
$$
I.A.Sellin,
S.D.Berry,
M.Breinig,
C.Bottcher, R,Latz,

M.Burkhard, H.Folgex, H.J.Frischkorn, K.o.Groeneveld,

D.Hofmann, P.Koschar,

Lecture notes in physics vol 213, (K.0.Groeneveld,

W.Meckbach, I.A.Sellin, ed), Berlin: Springer (1984) p. 109

[4] J.Kemmler, O.Heil, C.Biedermann, P.Koschar, H.Rothard,

K.Kroneberger, K.O.Groeneveld, A.Köver, G.Szabo, L.Gulyas,

D.Berenyi, P.Focke, W.Meckbach,

$3^{\text {rd }}$ Workshop on Ion-Atom collisions in Debrecen/Hungary, 1987

to appear in Lecture Notes in Physics (D.Berenyi ed.) 